\title{
Evolução da qualidade do substrato de uma área minerada no cerrado revegetada com Stylosanthes spp
}

\author{
$\overline{\text { Lucas C. R. Silva }{ }^{1} \& \text { Rodrigo S. Corrêa }}{ }^{2}$
}

\begin{abstract}
RESU MO
A retirada da camada superficial do solo e a escavação do subsolo pela mineração deixam expostos materiais inadequados ao estabelecimento e desenvolvimento de plantas. Nesses locais a regeneração natural é inci piente, de modo que intervenções que visem à melhoria do substrato são necessárias para o restabelecimento da vegetação. Este trabalho teve por objetivo avaliar a evolução física, química e biológica de um substrato minerado no Distrito Federal após a introdução de uma cobertura herbácea de Stylosanthes spp. 0 s resultados mostram que as operações necessárias para a implantação do estrato herbáceo e o desenvolvimento das plantas melhoraram significativamente os atributos avaliados. Os parâmetros químicos foram os mais modificados e os físicos, os que menos evoluíram após dois anos da revegetação. Houve, ainda, recuperação satisfatória do teor de matéria orgânica do substrato, mas a atividade microbiana permaneceu em cerca de $60 \%$ da encontrada em solos sob vegetação nativa de Cerrado.
\end{abstract}

Palavras-chave: recuperação, reabilitação, revegetação, mineração, carbono

\section{Evolution of substrate quality of a mined area in the Brazilian Savanna after revegetation with Stylosanthes spp}

\begin{abstract}
Removal of superficial soil layer and mining expose the material unsuitable for plant growth. In such areas, natural regeneration is incipient and intervention to improve substrate quality is necessary for the reestablishment of a vegetative cover. This study aimed to evaluate physical, chemical, and biological evolution of a mined substrate in the Federal District of Brazil after the establishment of a Stylosanthes spp. herbaceous cover. Results show that the operations necessary for planting and growth of plants improved all measured parameters. The chemical attributes of substrate were the most improved and physical characteristics were the ones that least evolved two years after the establishment of revegetation. There was a satisfactory recovery of organic matter content, but microbial activity represented only $60 \%$ of the value measured in soils under native vegetation.
\end{abstract}

Key words: recovery, land rehabilitation, revegetation, mining, carbon

1 School of Environmental Sciences, Universidade de Guelph, ON, Canadá. N1G 2W 1. E-mail: lucascrsilva@gmail.com

2 EFL/FT/U nB - Bolsista de Produtividade em Pesquisa do CN Pq. CP 04401, CEP 70910-900, Brasília, DF. Fone: (61) 9211-5452. Fax: (61) $3347-5458$. E-mail: rodmanga@yahoo.com.br 


\section{INTRODUÇÃO}

A exploração de materiais para a construção civil é a maior responsável pelas áreas agudamente degradadas no Distrito Federal (Corrêa, 2006). Nesses locais, a regeneração natural sobre os substratos expostos é lenta e pode demandar séculos para que uma comunidade clímax seja atingida (Ganade \& Brown, 2002; Begon et al., 2006), pois a retirada da camada superficial do solo deixa expostos materiais inadequados ao estabelecimento e desenvolvimento de plantas (Bezerra, 2006; Rodrigues et al., 2007).

As restrições ao estabelecimento de plantas sobre substratos minerados podem ser atribuídas à alta compactação da superfície, à baixa capacidade de armazenamento de água, falta de matéria orgânica, baixa capacidade de troca catiônica e redução da fertilidade (Goedert et al., 2002; Longo et al., 2005). Essas restrições podem, ainda, reduzir a biomassa microbiana de solo, limitar a condutância estomática, a eficiência na fixação de carbono e, consequentemente, o desenvolvimento de plantas capazes de se estabelecerem nesses locais (Silva \& Corrêa, 2008; Silveira et al., 2006).

A intervenção humana é capaz de acelerar o restabelecimento da vegetação, a restauração de locais minerados deve iniciar-se com a criação de condições topográficas, edáficas e ecológicas que impulsionem a sucessão natural (Anand \& Desrochers, 2004). Contudo, tradicionalmente projetos de recuperação priorizam o plantio de espécies arbóreas (Pinheiro et al., 2009) e pouco esforço tem sido investido na reconstrução de condições edáficas adequadas em substratos expostos pela mineração (Moraes Neto et al., 2003; Almeida \& Sanchez, 2005).

Segundo Silveira (2005) práticas de recuperação devem visar ao beneficiamento do substrato e à evolução de seus atributos físicos, químicos e biológicos. A implantação de um estrato herbáceo pode promover esse tipo de transformação, facilitando o processo de regeneração natural dos estratos arbóreo e arbustivo. Espécies herbáceas implantadas sobre superfícies mineradas criam condições apropriadas à germinação e ao estabelecimento de sementes e propágulos que, eventualmente, chegam ao local por meios próprios (Begon et al., 2006).

Os efeitos positivos de uma cobertura herbácea sobre superfícies mineradas são intensificados quando se utilizam espécies forrageiras nativas, especialmente leguminosas Fabaceae. Entre as diversas forrageiras existentes, o gênero Stylosanthes possui espécies de ocorrência natural no Cerrado; a maioria delas é perene, apresenta potente sistema radicular, estabelece simbiose com bactérias fixadoras de nitrogênio, é tolerante à seca e dotada de grande capacidade de colonizar solos de baixa fertilidade (Godoi et al., 2008).

A associação desses atributos à natividade de várias espécies do gênero Stylosanthes o habilita a ser utilizado em áreas mineradas situadas em unidades de conservação no cerrado. Dessa forma, este trabalho visa avaliar a evolução das qualidades física, química e biológica de um substrato minerado após o estabelecimento de um estrato herbáceo composto por Stylosanthes spp.

\section{MATERIAL E MÉTODOS}

O experimento foi instalado em uma jazida de cascalho explotada, situada na Área de Relevante Interesse Ecológico Santuário de Vida Silvestre do Riacho Fundo, Distrito Federal. A cava, lavrada na década de 1970, apresenta 1,5 ha de extensão, Cambissolo Háplico eutrófico, como solo original, e cerca de um $1 \mathrm{~m}$ de profundidade de corte. A área foi terraceada em 2002 e até a instalação do experimento, em 2003, não havia sinais de regeneração natural no local nem presença de macrofauna de solo. $\mathrm{O}$ substrato exposto foi escarificado a $20 \mathrm{~cm}$ de profundidade, adubado com $20 \mathrm{~m}^{3} \mathrm{ha}^{-1}$ de composto de lixo (30\% de umidade, densidade de $\left.0,4 \mathrm{Mg} \mathrm{m}^{-3}\right), 870 \mathrm{~kg} \mathrm{ha}^{-1}$ de calcário dolomítico 90\% PRNT e $435 \mathrm{~kg} \mathrm{ha}^{-1}$ de NPK - 4:14:8. Quinze dias após a aplicação dos insumos foram incorporados $2 \mathrm{~kg} \mathrm{ha}^{-1}$ de sementes de Stylosanthes spp. (produto comercial contendo 60\% de $S$. capitata, $25 \%$ de $S$. guianensis e $15 \%$ de S. macrocephala) na profundidade de $5 \mathrm{~cm}$. Essa área será referida, neste trabalho, como cascalheira revegetada, enquanto parte do substrato minerado, aqui referido apenas como cascalheira, não foi escarificado, adubado ou semeado. Avaliou-se um local não minerado e adjacente à jazida explotada para servir de área de solo controle.

Cinco amostras compostas de substrato e solo, formadas por dez subamostras deformadas, foram coletadas logo após a semeadura do Stylosanthes spp. e, dois anos depois, entre 0 e $20 \mathrm{~cm}$ de profundidade, em cada um dos locais (cascalheira, cascalheira revegetada e solo controle).

A análise textural seguiu o método da pipeta. A concentração de matéria orgânica foi determinada pelo método de Walkley-Black. O pH foi determinado em solução solo:água $(1: 2,5)$. Nitrogênio total ( $\mathrm{N}$-total) foi avaliado pelo método Kjeldahl de destilação. Fósforo disponível (P-disponível) e potássio trocável (K-trocável) foram extraídos com solução Mehlich I $\left(0,025 \mathrm{~N} \mathrm{H}_{2} \mathrm{SO}_{4}+0,05 \mathrm{~N} \mathrm{HCl}\right)$; determinaramse as concentrações desses elementos em espectrofotômetro UV-vis e chama, respectivamente. Alumínio $\left(\mathrm{Al}^{+3}\right)$, cálcio $\left(\mathrm{Ca}^{+2}\right)$ e magnésio $\left(\mathrm{Mg}^{+2}\right)$ foram extraídos com uma solução de $\mathrm{KCl} 1 \mathrm{~N}$. A concentração de $\mathrm{Al}^{+3}$ foi determinada por titulação com $\mathrm{NaOH}(0,01 \mathrm{~N})$ e as concentrações de $\mathrm{Ca}^{+2}$ e $\mathrm{Mg}^{+2}$ obtidas em espectrofotômetro de absorção atômica. A acidez potencial $\left(\mathrm{H}^{+}+\mathrm{Al}^{+3}\right)$ foi determinada por meio de uma solução tamponada de acetado de cálcio $0,5 \mathrm{M}$ e posterior titulação com $\mathrm{NaOH}$ 0,05 M. Calcularam-se, a partir dos resultados obtidos, a capacidade de troca catiônica (CTC a pH 7), a soma de bases (S) e a porcentagem de saturação por bases (V\%) do solo e dos substratos conforme (EMBRAPA, 1997).

Para a determinação da biomassa microbiana amostras do substrato minerado (cascalheira e cascalheira revegetada) foram coletadas no período chuvoso (janeiro) e armazenadas no mesmo dia em câmara fria $\left(4^{\circ} \mathrm{C}\right)$. A biomassa microbiana corresponde ao material orgânico contido nas bactérias, actinomicetos, fungos, algas e microfauna do solo, que respondem a, aproximadamente, 5\% da matéria orgânica total do solo (Parton et al., 1994). Avaliou-se o carbono microbiano do solo e dos substratos através do método 
da fumigação-extração. A fumigação com clorofórmio $\left(\mathrm{CHCl}_{3}\right)$ libera material celular em razão do rompimento da membrana citoplasmática. O material liberado é recuperado por extração com sulfato de potássio $\left(\mathrm{K}_{2} \mathrm{SO}_{4}\right) \operatorname{logo}$ após a fumigação.

O carbono microbiano extraído das amostras é então calculado pela equação:

$$
\mathrm{C}=(\mathrm{Vb}-\mathrm{Va}) \times \mathrm{N} \times 0,003 \times 50 \times(8 \mathrm{Ps})^{-1} \times 10^{6}
$$

em que:

$\mathrm{C}$ - é o carbono microbiano extraído, $\mathrm{mg} \mathrm{kg}^{-1}$

$\mathrm{Vb}$ - é o volume do sulfato ferroso amoniacal gasto na titulação da solução controle, $\mathrm{mL}$

Va - é o volume gasto na titulação da amostra, $\mathrm{mL}$

$\mathrm{N}$ - é a normalidade da solução titulante - $\left(\mathrm{NH}_{4}\right)_{2}$ $\mathrm{Fe}\left(\mathrm{SO}_{4}\right)_{2} \cdot 6 \mathrm{H}_{2} \mathrm{O}$

Ps - é a massa de solo/substrato seco, g

A biomassa microbiana corresponde ao fluxo de carbono verificado entre as amostras fumigadas e não fumigadas, segundo a equação:

$$
\mathrm{BMS}=\mathrm{FC} \times \mathrm{kc}^{-1}
$$

em que:

BMS - é a biomassa de carbono microbiano do solo/ substrato em $\mathrm{mg}$ de $\mathrm{C}$ por $\mathrm{kg}$ de terra (ou $\left.\mu \mathrm{g} \mathrm{g}^{-1}\right), \mathrm{mg} \mathrm{kg}^{-1}$

FC - é o fluxo obtido da diferença entre a quantidade de $\mathrm{C}\left(\mathrm{mg} \mathrm{kg}^{-1}\right)$ recuperada no extrato da amostra fumigada e a recuperada na amostra não fumigada

kc - é o fator de correção para os solos do Brasil, que no caso é de 0,35

Coletaram-se, também, amostras indeformadas de solo e substrato entre a profundidade 0 e $20 \mathrm{~cm}$, com o auxílio de anéis volumétricos de $100 \mathrm{~cm}^{3}$, com dez repetições por área. As referidas amostras foram utilizadas para determinação da porosidade e densidade do solo e substratos. Para se determinar a porosidade total (PSR) considerou-se o valor de $2,65 \mathrm{~g} \mathrm{~cm}^{-3}$ como a densidade de partículas do solo e dos substratos. A porosidade total foi calculada pela razão entre densidade do solo $\left(\rho_{\mathrm{b}}\right)$ e densidade de partículas, conforme a equação:

$$
\operatorname{PSR}(\%)=\left(1-\frac{\rho_{\mathrm{b}}}{2,65}\right) \times 100
$$

Determinou-se a densidade do solo e os substratos $\left(\rho_{b}\right)$ pela razão entre a massa seca e o volume de material no anel volumétrico. A microporosidade foi determinada em centrífuga, sob sucção de $6 \mathrm{kPa}$, e a macroporosidade pela diferença entre PSR e a microporosidade. A taxa de infiltração de água $\left(\mathrm{cm} \mathrm{h}^{-1}\right)$ e a infiltração acumulada em $2,5 \mathrm{~h}$ nas áreas de estudo foram medidas em triplicata por meio de infiltrômetros de anéis concêntricos (EMBRAPA, 1997). Os cilindros interno e externo apresentavam 24 e $48 \mathrm{~cm}$ de diâmetro e 25 e $15 \mathrm{~cm}$ de altura, respectivamente.
O composto de lixo utilizado na área tratada da cascalheira foi digerido a $200{ }^{\circ} \mathrm{C}$ em mistura de ácido fluorídrico, ácido nítrico e ácido perclórico concentrados, para a determinação das concentrações totais de nutrientes, utilizandose os mesmos métodos descritos acima. Os resultados estão apresentados na Tabela 1.

Os dados obtidos foram submetidos a análise de variância e comparados pelo teste de múltiplas comparações de Tukey $(\mathrm{P}<0,05)$, com auxílio do pacote estatístico SAS.

Tabela 1. Caracterização do composto de lixo (base seca) utilizado como fonte de matéria orgânica na implantação da cobertura herbácea na cascalheira tratada (média \pm desvio padrão)

\begin{tabular}{lr}
\hline Parâmetro & Média \pm desvio padrão \\
pH em água $(1: 2,5)$ & $7,88 \pm 0,19$ \\
Matéria orgânica $\left(\mathrm{g} \mathrm{kg}^{-1}\right)$ & $111,6 \pm 8,74$ \\
$\mathrm{~N}$-total $\left(\mathrm{g} \mathrm{kg}^{-1}\right)$ & $9,8 \pm 0,53$ \\
Ca-total $\left(\mathrm{g} \mathrm{kg}^{-1}\right)$ & $33,0 \pm 1,32$ \\
Mg-total $\left(\mathrm{g} \mathrm{kg}^{-1}\right)$ & $2,8 \pm 0,14$ \\
$\mathrm{~K}$-total $\left(\mathrm{g} \mathrm{kg}^{-1}\right)$ & $12,8 \pm 3,69$ \\
P-total $\left(\mathrm{g} \mathrm{kg}^{-1}\right)$ & $1,2 \pm 0,35$ \\
Cu-total $\left(\mathrm{mg} \mathrm{kg}^{-1}\right)$ & $127,6 \pm 40,5$ \\
Fe-total $\left(\mathrm{mg} \mathrm{kg}^{-1}\right)$ & $463,8 \pm 21,5$ \\
Zn-total $\left(\mathrm{mg} \mathrm{kg}^{-1}\right)$ & $527,0 \pm 80,2$ \\
Mn-total $\left(\mathrm{mg} \mathrm{kg}^{-1}\right)$ & $304,2 \pm 35,6$ \\
Ni-total $\left(\mathrm{mg} \mathrm{kg}^{-1}\right)$ & traço \\
Pb-total $\left(\mathrm{mg} \mathrm{kg}^{-1}\right)$ & traço \\
Cd-total $\left(\mathrm{mg} \mathrm{kg}^{-1}\right)$ & traço \\
\hline
\end{tabular}

\section{RESULTADOS E DISCUSSÃO}

\section{Parâmetros físicos}

Os resultados da análise textural revelaram significativa diferença entre a granulometria dos substratos e do solo utilizado como controle (Tabela 2). A camada superficial do solo da área controle é arenosa, enquanto os substratos analisados são argilosos. Substratos expostos pela mineração no Cerrado são frequentemente argilosos e compactados (Corrêa, 2006), e essas características podem restringir o estabelecimento espontâneo de espécies, dificultar a regeneração natural (Longo et al., 2005) e alterar a composição da flora original da área (Ruggiero et al., 2002).

Valores elevados de densidade $\left(\rho_{b}\right)$ representam um outro impeditivo ao estabelecimento de plantas em solos e substratos (Goedert et al., 2002). O maior valor aqui encontrado $\left(\rho_{b}=1,6\right)$ foi mensurado na cascalheira (Figura 1). Tráfego de máquinas e impacto de chuvas sobre substratos desnudos são fatores que contribuem para compactar superfícies mineradas (Corrêa, 2006). A escarificação da superfície e a incorporação de matéria orgânica antes da semeadura do Stylosanthes spp. não reduziram significativamente os valores de $\rho_{\mathrm{b}}$ (Figura 1); todavia, dois anos de desenvolvimento da cobertura herbácea na cascalheira revegetada foram suficientes para reduzir os valores de $\rho_{\mathrm{b}}$ em $25 \%$ e aproximálos dos valores do solo controle (Figura 1).

Não há consenso sobre o nível crítico de $\rho_{\mathrm{b}}$ que impediria o desenvolvimento vegetal, porém valores assumidos para 
a região estão normalmente entre 1,4 e $1,8 \mathrm{Mg} \mathrm{m}^{-3}$ (Goedert et al., 2002). As sementes de Stylosanthes spp. foram incorporadas ao substrato com $\rho_{b}=1,5 \mathrm{Mg} \mathrm{m}^{-3}$ e se desenvolveram satisfatoriamente. A capacidade de a raiz penetrar e explorar o solo e de a planta se desenvolver não dependem apenas da resistência física do material mas, também, de sua fertilidade (Gonçalves \& Mello, 2004); portanto, apesar da escarificação se ter mostrado insuficiente para reduzir a densidade do substrato minerado, a incorporação de matéria orgânica e de fertilizantes foi suficiente para proporcionar um ambiente favorável ao desenvolvimento da cobertura herbácea.

Tabela 2. Caracterização dos substratos e do solo controle entre $0-20 \mathrm{~cm}$ de profundidade das três subáreas avaliadas (média \pm desvio padrão)

\begin{tabular}{lccc}
\hline Parâmetro & Cascalheira & $\begin{array}{c}\text { Cascalheira } \\
\text { revegetada }\end{array}$ & Solo controle \\
pH em água $(1: 2,5)$ & $6,71 \pm 0,18$ & $6,97 \pm 0,06$ & $5,72 \pm 0,11$ \\
Argila $\left(\mathrm{g} \mathrm{kg}^{-1}\right)$ & $481 \pm$ & 479 & 380 \\
Silte $\left(\mathrm{g} \mathrm{kg}^{-1}\right)$ & 150 & 151 & 10 \\
Areia $\left(\mathrm{g} \mathrm{kg}^{-1}\right)$ & 369 & 370 & 610 \\
Matéria orgânica $\left(\mathrm{g} \mathrm{kg}^{-1}\right)$ & $5,7 \pm 0,3$ & $13,4 \pm 0,5$ & $14,5 \pm 0,6$ \\
$\mathrm{~N}$-total $\left(\mathrm{g} \mathrm{kg}^{-1}\right)$ & $6 \pm 0,0$ & $11 \pm 1$ & $10 \pm 1$ \\
$\mathrm{Ca}\left(\mathrm{cmol}_{\mathrm{c}} \mathrm{dm}^{-3}\right)$ & $1,67 \pm 0,19$ & $1,59 \pm 0,17$ & $1,17 \pm 0,06$ \\
$\mathrm{Mg}\left(\mathrm{cmol}_{\mathrm{c}} \mathrm{dm}^{-3}\right)$ & $0,24 \pm 0,02$ & $0,62 \pm 0,06$ & $0,26 \pm 0,01$ \\
$\mathrm{Al}\left(\mathrm{cmol}_{\mathrm{c}} \mathrm{dm}^{-3}\right)$ & $0,00 \pm 0,00$ & $0,00 \pm 0,00$ & $0,00 \pm 0,00$ \\
$\mathrm{H}^{+}+\mathrm{Al}^{+3}\left(\mathrm{cmol}_{\mathrm{c}} \mathrm{dm}^{-3}\right)$ & $0,00 \pm 0,00$ & $0,16 \pm 0,14$ & $3,63 \pm 0,15$ \\
$\mathrm{~K}\left(\mathrm{cmol}_{\mathrm{c}} \mathrm{dm}^{-3}\right)$ & $0,04 \pm 0,01$ & $0,31 \pm 0,01$ & $0,14 \pm 0,00$ \\
$\mathrm{~S}\left(\mathrm{cmol}_{\mathrm{c}} \mathrm{dm}^{-3}\right)$ & 1,9 & 2,5 & 1,6 \\
$\mathrm{CTC}\left(\mathrm{cmol}_{\mathrm{c}} \mathrm{dm}^{-3}\right)$ & 1,9 & 2,7 & 5,2 \\
$\mathrm{~V}(\%)$ & 100 & 94 & 30 \\
$\mathrm{BMS}\left(\mathrm{mg} \mathrm{kg}^{-1}\right)$ & 3,8 & 211 & - \\
$\mathrm{P}$-disponível $\left(\mathrm{mg} \mathrm{kg}^{-1}\right)$ & $0,93 \pm 0,21$ & $11,3 \pm 2,70$ & $2,6 \pm 0,29$ \\
$\mathrm{Cu}\left(\mathrm{mg} \mathrm{kg}^{-1}\right)$ & $0,93 \pm 0,15$ & $1,97 \pm 0,23$ & $1,13 \pm 0,15$ \\
Fe $\left(\mathrm{mg} \mathrm{kg}^{-1}\right)$ & $20,93 \pm 3,35$ & $41,70 \pm 2,81$ & $55,53 \pm 4,67$ \\
Mn $\left(\mathrm{mg} \mathrm{kg}^{-1}\right)$ & $2,87 \pm 0,47$ & $7,47 \pm 0,49$ & $6,00 \pm 0,26$ \\
Zn $\left(\mathrm{mg} \mathrm{kg}^{-1}\right)$ & $1,10 \pm 0,10$ & $8,43 \pm 0,31$ & $6,20 \pm 0,46$ \\
\hline
\end{tabular}

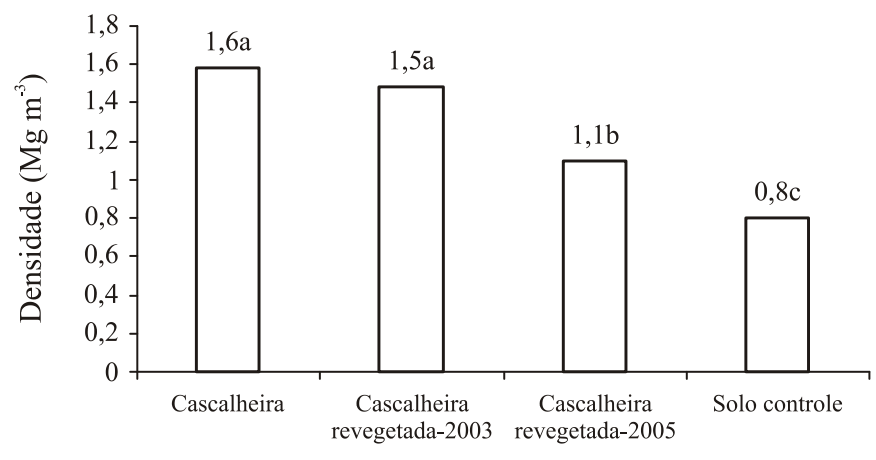

Figura 1. Densidade do solo e dos substratos $\left(\rho_{b}\right)$ entre a profundidade $0 \mathrm{e}$ $20 \mathrm{~cm}$. Médias de mesma letra não apresentam diferenças significativas $(\mathrm{P}<0,05)$ pelo teste de Tukey

O substrato da cascalheira apresentou taxas de infiltração de água aquém das necessárias para absorver uma chuva de intensidade média no Distrito Federal (Figuras 2 e 3). A escarificação e a incorporação de matéria orgânica, para possibilitar a semeadura do Stylosanthes spp., elevaram em até três vezes a taxa de infiltração do substrato minerado. Após dois anos, o desenvolvimento radicular da cobertura herbácea quase duplicou a capacidade de infiltração acumulada do substrato da área (Figura 3). Desenvolvimento radicular geralmente aumenta a taxa de infiltração por meio da escavação de canais e mudanças na estrutura de substratos (Joshua et al., 1998). Neste sentido, o desenvolvimento do Stylosanthes spp. aumentou a porosidade total em aproximadamente $45 \%$ e alterou a proporção entre macroporos e microporos em relação ao substrato escarificado e tratado com matéria orgânica antes da semeadura (Tabela 3). Apesar disso, a escarificação, a incorporação de matéria orgânica e os dois anos de desenvolvimento do estrato herbáceo não foram capazes de elevar a infiltração acumulada a níveis semelhantes aos verificados no solo controle. $\mathrm{O}$ melhor resultado observado corresponde a $63 \%$ da infiltração acumulada no solo não escavado (Figura 3).

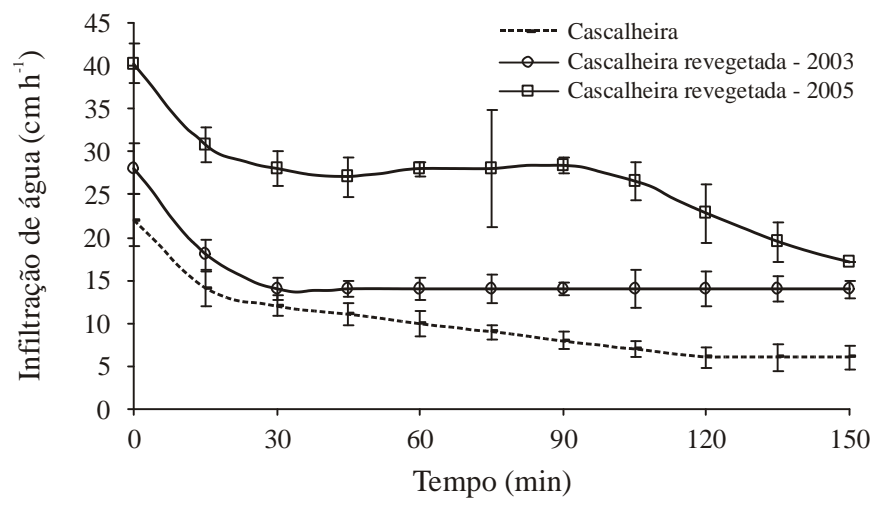

Figura 2. Taxa de infiltração na cascalheira e na cascalheira revegetada

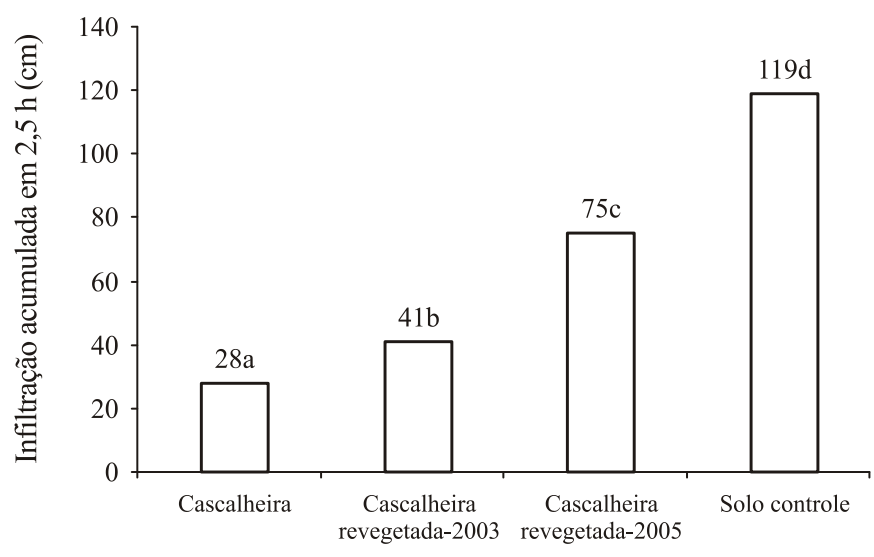

Figura 3. Infiltração de água em $2,5 \mathrm{~h}$ de observação. Médias de mesma letra nẫo apresentam diferenças significativas $(\mathrm{P}<0,05)$ pelo teste de Tukey

Tabela 3. Porosidade na profundidade de $0-20 \mathrm{~cm}$ na cascalheira escarificada e após dois anos de desenvolvimento do estrato herbáceo (média \pm desvio padrão)

\begin{tabular}{lccc}
\hline Situação & $\begin{array}{c}\text { Microporosidade } \\
\text { (\%) }\end{array}$ & $\begin{array}{c}\text { Macroporosidade } \\
\text { (\%) }\end{array}$ & $\begin{array}{c}\text { Porosidade total } \\
\text { (\%) }\end{array}$ \\
$\begin{array}{l}\text { Cascalheira } \\
\text { escarificada - } 2003\end{array}$ & $33,2 \pm 1,2$ & $7 \pm 0,3$ & $40,2 \pm 2,1$ \\
$\begin{array}{l}\text { Cascalheira } \\
\text { revegetada - 2005 }\end{array}$ & $38,3 \pm 0,9$ & $20,1 \pm 1,1$ & $58,4 \pm 3,2$ \\
\hline
\end{tabular}




\section{Parâmetros químicos}

A adubação do substrato minerado se baseou em recomendações para o plantio de Stylosanthes spp. (EMBRAPA, 1993; Godoi et al., 2008) e foi realizada apesar da considerável fertilidade da área minerada (Tabela 2). Em solos jovens, como o Cambissolo, é comum a presença de saprólitos nos horizontes mais profundos, cuja composição mineralógica é dominada por argilominerais do grupo da caulinita (Araújo et al., 2005). Onde há predominância de caulinita, o substrato tem caráter básico ou pouco ácido (Tabela 2), com valores de óxidos de alumínio inexpressivos, de modo que fósforo (P) e as bases se tornam disponíveis (Brady, 1989).

Outros autores verificaram valores de acidez potencial maiores em solos que em substratos minerados (Longo et al., 2005). Relatam, também, que a soma de bases não variava significativamente entre solos e substratos minerados por eles estudados. As diferenças na CTC e na saturação por bases (V\%) eram determinadas por diferenças da acidez potencial $-\mathrm{H}^{+}+\mathrm{Al}^{+3}$ (Longo et al., 2005), da mesma forma que aqui observado (Tabela 2). O substrato minerado deste trabalho apresenta, portanto, em alguns parâmetros, condição nutricional superior à verificada em Cambissolos sob vegetação nativa de Cerrado. Entretanto, a implantação de Stylosanthes spp. demanda matéria orgânica, fósforo e potássio em níveis superiores aos encontrados na jazida explotada (EMBRAPA, 1993; Godoi et al., 2008).

A concentração de P-disponível em solos de Cerrado varia entre 0,1 e $16,5 \mathrm{mg} \mathrm{kg}^{-1}$, mas $90 \%$ dos solos em áreas de Cerrado apresentavam valores de P-disponível inferiores a $2 \mathrm{mg} \mathrm{kg}^{-1}$ (Sousa \& Lobato, 2004). A concentração de P-disponível na cascalheira revegetada, após dois anos de desenvolvimento do estrato herbáceo, foi elevada de $0,93 \mathrm{mg} \mathrm{kg}^{-1}$ para $11,3 \mathrm{mg} \mathrm{kg}^{-1}$ (Tabela 2). Considerando-se parâmetros agronômicos, o teor ideal de P-disponível em solos de Cerrado com 36 - 60\% de argila se situa entre 8 e $12 \mathrm{mg} \mathrm{kg}^{-1}$ (Sousa \& Lobato, 2004). Desta forma, dois anos após a intervenção na jazida o substrato minerado evoluiu da condição de P-disponível muito baixo para uma condição ideal.

Constatou-se, ainda, o incremento em concentrações de $\mathrm{N}$-total, quando se compara o substrato da cascalheira revegetada ao da cascalheira antes de ser revegetada (Tabela 2). As maiores concentrações de nitrogênio e fósforo encontradas no substrato podem estar relacionadas ao maior teor de matéria orgânica, resultado do desenvolvimento da vegetação e da produção de biomassa pela leguminosa - Fabaceae no local (Silva et al., 2008). Stylosanthes spp. se associam a Bradyrhizobium spp e fungos micorrízicos, que podem enriquecer solos e substratos (Carneiro et al., 1999).

\section{Matéria orgânica}

Um dos indicadores de maior importância na avaliação da evolução da qualidade de um solo ou substrato é o teor de matéria orgânica (Doran \& Parkin, 1994). A dose de $20 \mathrm{~m}^{3} \mathrm{ha}^{-1}$ de composto de lixo aplicada ao substrato minerado resultou em $1,57 \mathrm{~m}^{3} \mathrm{ha}^{-1}$ de matéria orgânica efetivamente incorporada, considerando-se a umidade e o teor de cinzas presentes no composto aplicado. Desta forma, houve uma adição de $0,8 \mathrm{~g} \mathrm{~kg}^{-1}$ de matéria orgânica ao substrato; contudo, a análise da matéria orgânica após dois anos da revegetação mostrou teores de 13,4 $\mathrm{g} \mathrm{kg}^{-1}$ (Tabela 2).

Em solos minerais bem drenados o teor de matéria orgânica varia de 20 a $60 \mathrm{~g} \mathrm{~kg}^{-1}$ (Brady, 1989). Em áreas mineradas no Distrito Federal, a concentração varia entre 4 e $9 \mathrm{~g} \mathrm{~kg}^{-1}$ (Corrêa, 2006; Silva \& Corrêa, 2008). Assim, os teores de matéria orgânica no substrato da cascalheira não revegetada $\left(5,7 \mathrm{~g} \mathrm{~kg}^{-1}\right)$ estão conforme os valores encontrados em áreas mineradas no Distrito Federal. A incorporação de $20 \mathrm{~m}^{-3}$ ha de composto de lixo elevou o teor de matéria orgânica para $6,5 \mathrm{~g} \mathrm{~kg}^{-1}$, mas o grande incremento de matéria orgânica no substrato minerado foi resultado do desenvolvimento do estrato herbáceo implantado na área $(6,5$ a $\left.13,4 \mathrm{~g} \mathrm{~kg}^{-1}\right)$. Após dois anos de implantação do Stylosanthes spp., o teor de matéria orgânica aproximou-se do valor de $14,5 \mathrm{~g} \mathrm{~kg}^{-1}$ encontrado no solo controle, o que representa, considerando-se a profundidade analisada $(0-20 \mathrm{~cm})$, que a produção de biomassa da cobertura herbácea acrescentou $13,8 \mathrm{~m}^{3} \mathrm{ha}^{-1}$ de matéria orgânica ao substrato da área minerada. Para se aumentar o teor de matéria orgânica a esse nível por meio da adição de composto, seria necessário aplicar a dose de $179 \mathrm{~m}^{3} \mathrm{ha}^{-1}$, ou aproximadamente nove vezes a quantidade incorporada ao substrato na época da revegetação.

\section{Biomassa de carbono microbiano}

A recuperação de áreas degradadas está fortemente limitada por atributos microbiológicos e bioquímicos do solo (Silveira et al., 2006). Indicadores biológicos de qualidade do solo retratam condições de degradação e síntese de substâncias orgânicas, fundamentais para a agregação de partículas e para a disponibilidade de nutrientes às plantas (Doran \& Parkin, 1994). O teor de carbono da biomassa microbiana ressalta melhor a condição de um substrato que o teor de matéria orgânica, pois a microbiota do solo responde mais intensamente e rapidamente a variações no ambiente edáfico (Saffigna et al., 1989).

O estrato herbáceo da cascalheira revegetada foi capaz de proporcionar, em seus dois primeiros anos de desenvolvimento, um ambiente favorável à colonização de micro-organismos de solo, pois os valores de biomassa de carbono microbiano (BMS) se elevaram de $3,8 \mathrm{mg} \mathrm{kg}^{-1}$ (cascalheira) para $211 \mathrm{mg} \mathrm{kg}^{-1}$ na cascalheira revegetada (Tabela 2). A biomassa microbiana representa a principal parte do compartimento lábil de muitos nutrientes a serem disponibilizados para plantas durante seu desenvolvimento (Rice et al., 1996). Ela é responsável pela fração de reciclagem mais rápida da matéria orgânica no solo e uma mudança significativa neste parâmetro representa grande melhoria qualitativa na capacidade de suporte do substrato, em relação à vegetação.

Existe estreita associação entre o desenvolvimento vegetal e a atividade microbiana de solos. A inoculação de fungos micorrízicos, por exemplo, auxilia o estabelecimento de vegetação herbácea sobre substratos minerados e maximiza os efeitos de insumos utilizados na revegetação (Martins et al., 1999). Fungos micorrízicos arbusculares são encontrados em solos degradados e podem interferir na composição, na competição e na sucessão das comunidades vegetais (Allen \& Allen, 1984). A produção de matéria orgânica e a recuperação 
da comunidade microbiana do solo e suas relações com a ciclagem e assimilação de nutrientes têm, portanto, papel fundamental nas transformações que equilibram e sustentam ecossistemas (Silva et al., 2008). A maioria das plantas que ocorre espontaneamente em áreas mineradas apresenta simbiose com fungos micorrízicos arbusculares e é por eles beneficiadas em seu crescimento e sobrevivência (Allen \& Allen, 1984).

Desta forma, o acentuado incremento na biomassa microbiana indica que está havendo restauração biológica do substrato, que pode ser tomada como indicação favorável de adequação e sustentabilidade (Anderson \& Domsch, 1993). Todavia, o uso do solo e a época de avaliação influenciam significativamente os valores da biomassa de carbono microbiano - BMS (Ferreira et al., 2007). Esses autores encontraram entre 345 e $566 \mathrm{mg} \mathrm{kg}^{-1}$ de BMS na camada superficial de um solo sob Cerrado no mês de janeiro. Araújo et al. (2007) encontraram $532 \mathrm{mg} \mathrm{kg}^{-1}$ de BMS em um solo sob Cerrado nativo, $400 \mathrm{mg} \mathrm{kg}^{-1} \mathrm{em}$ pastagem nativa, $235 \mathrm{mg} \mathrm{kg}^{-1} \mathrm{em}$ pastagem plantada e apenas $106 \mathrm{mg} \mathrm{kg}^{-1} \mathrm{em}$ um solo sob Pinus sp.

$\mathrm{O}$ valor de $211 \mathrm{mg} \mathrm{kg}^{-1}$ de BMS mensurado neste trabalho na cascalheira revegetada corresponde a $37-61 \%$ dos valores indicados por Ferreira et al. (2007) e Araújo et al. (2005) e é superior ao valor encontrado em solo sob Pinus sp (Araújo et al., 2007). O substrato da cascalheira apresentou $3,8 \mathrm{mg} \mathrm{kg}^{-1}$ de BMS, que corresponde a apenas cerca de $2 \%$ da concentração medida no substrato coberto por Stylosanthes spp. e $1 \%$ do menor valor encontrado por Ferreira et al. (2007) para áreas nativas de cerrado.

\section{CONCLUSÕES}

1. A escarificação e a incorporação de matéria orgânica e de fertilizantes permitiram o estabelecimento e desenvolvimento de um estrato herbáceo de Stylosanthes spp. sobre o substrato exposto da cascalheira.

2. Redução da densidade do substrato, aumento da capacidade de infiltração de água, dos teores de fósforo disponível, nitrogênio total e da capacidade de troca catiônica do substrato foram mais pronunciados em virtude do desenvolvimento do estrato herbáceo do que pelos tratamentos mecânicos e químicos que precederam na semeadura do Stylosanthes spp.

3. O desenvolvimento do estrato herbáceo foi o principal responsável pela evolução física, química e biológica do substrato minerado.

4. Os teores de matéria orgânica no substrato revegetado se aproximaram dos níveis encontrados em solos não minerados; entretanto, a biomassa de carbono microbiano, parâmetro que reflete características qualitativas do substrato, permaneceu aquém dos valores encontrados em solos não degradados.

\section{LITERATURA CITADA}

Allen, E. B.; Allen, M. F. Competition between plants of different successional stages: mycorrhizae as regulators. Canadian Journal of Botany, v.62, n.12, p. 2625-2629, 1984.
Almeida, R. O. P. O.; Sanchez, L. E. Revegetação de áreas de mineração: critérios de monitoramento e avaliação do desempenho. Revista Árvore, v.29, n.1, p.47-54, 2005.

Anand, M.; Desrochers, R. E. Quantification of restoration success using complex systems concepts and models. Restoration Ecology, v.12, n.1, p.117-123, 2004.

Anderson, T. H.; Domsch, K. H. The metabolic quotient for $\mathrm{CO} 2$ (qCO2) as a specific activity parameter to assess the effects of environmental conditions, such as $\mathrm{pH}$, on the microbial biomass of forest soils. Soil Biology and Biochemistry, v.25, n.3, p.393-395, 1993.

Araújo, F. S.; Martins, S.V.; Neto, J. A. M.; Lani, J. L.; Pires, I. E. Florística da vegetação arbustivo - arbórea colonizadora de uma área degradada por mineração de caulim, em Brás Pires, MG. Revista Árvore, v.29, n.6, p.983-992, 2005.

Araújo, R.; Goedert, W. J.; Lacerda, M. P. C. Qualidade de um solo sob diferentes usos e sob cerrado nativo. Revista Brasileira de Ciência do Solo, v.31, n.5, p.1099-1108, 2007.

Begon, M.; Harper, J. L.; Townsend, C. R. Ecology: Individuals, populations and communities. 4.ed. Boston: Blackwell Scientific Publications, 2006. 759p.

Bezerra, F. B. Lodo de esgoto em revegetação de área degradada. Pesquisa Agropecuária Brasileira, v.41, n.3, p.469-476, 2006.

Brady, N. C. Natureza e propriedades dos solos. 5.ed. Rio de Janeiro: Freitas Bastos, 1989. 647p.

Carneiro, M. A. C.; Siqueira, J. O.; Curi, N.; Moreira, F. M. S. Efeitos da inoculação de fungos micorrízicos arbusculares e da aplicação de fósforo no estabelecimento de forrageiras em solo degradado. Pesquisa Agropecuária Brasileira, v.34, n.9, p.1669-1677, 1999.

Corrêa, R. S. Recuperação de áreas degradadas pela mineração no Cerrado: Manual para revegetação. 1.ed. Brasília: Universa, 2006. 187p.

Doran, J. W.; Parkin, T. B. Defining and assessing soil quality. In: Doran, J. W.; Coeman, D. C.; Bezdicek, D. F.; Stewart, B. A. (eds.). Defining soil quality for sustainable environment. Madison: Soil Science Society of America, 1994. cap.1, p.3-21.

EMBRAPA - Empresa Brasileira d Pesquisa Agropecuária. Recomendações técnicas para o estabelecimento e utilização do Stylosanthes guianensis cv. Mineirão. Planaltina: EmbrapaCPAC/CNPGC, 1993. 61p. Circular Técnica

EMBRAPA - Empresa Brasileira d Pesquisa Agropecuária. Manual de métodos de análise de solo. Rio de Janeiro: Centro Nacional de Pesquisa de Solos, 1997. 212p.

Ferreira, E. A. B.; Resck, D. V. S.; Gomes, A. C.; Ramos, M. L. G. Dinâmica do carbono da biomassa microbiana em cinco épocas do ano em diferentes sistemas de manejo do solo no Cerrado. Revista Brasileira de Ciência do Solo, v.31, n.6, p.1625-1635, 2007.

Ganade, G.; Brown, V. K. Succession in old pastures of Central Amazonia: Role of soil fertility and plant litter. Ecology, v.83, n.3, p.743-754, 2002.

Godoi, E. L.; Borges, J. D.; Leandro, W. M. Índices de cobertura vegetal e fitomassa de Stylosanthes guianensis cv. mineirão em área degradada fertilizada com adubo e biossólido. Pesquisa Agropecuária Tropical, v.38, n.1, p.21-26, 2008.

Goedert, W. J.; Schermack, M. J.; Freitas, F. C. Estado de compactação do solo em áreas cultivadas no sistema de plantio direto. Pesquisa Agropecuária Brasileira, v.37, n.2, p.233-227, 2002. 
Gonçalves, J. L. M.; Mello, S. L. M. The root system of trees. In: Gonçalves, J. L. M.; Benedetti, V. (ed.). Forest nutrition and fertilization. Piracicaba: Instituto de Pesquisas Florestais e Estudos Florestais, 2004. p.223-267.

Joshua W. D.; Michalk D. L.; Curtis I. H.; Salt, M.; Osborne. G. J. The potential for contamination of soil and surface waters from sewage sludge (biosolids) in a sheep grazing study. Geoderma, v.84, n.1-3, p.135-156, 1998.

Longo R. M.; Ribeiro A. I.; Melo W. J. Caracterização física e química de áreas mineradas pela extração de cassiterita. Bragantia, v.64, n.1, p.101-107, 2005.

Martins, C. R.; Miranda J. C. C.; Miranda L. N. Contribuição de fungos micorrízicos arbusculares nativos no estabelecimento de Aristida setifolia (Kunth.) em áreas degradadas do cerrado. Pesquisa Agropecuária Brasileira, v.34, n.4, p.665-674, 1999.

Moraes Neto, S. P.; Gonçalves, J. L. de M.; Arthur Jr., J. C.; Ducatti, F.; Aguirre, J. H. Fertilização de mudas de espécies arbóreas nativas e exóticas. Revista Árvore, v.27, n.2, p.129-137, 2003.

Parton, W. J.; Woomer, P. L.; Martin, A. Modeling soil organic matter dynamics and plant productivity in tropical ecosystems. In: Woomer, P. L.; Swift, M. J. (ed.). The biological management of tropical soil fertility. New York: Wiley, 1994. p.171-188.

Pinheiro, C. de Q.; Corrêa, R. S.; Silveira, I. M.; Jesus, R. S.; Jorge, R. R. de A. Análise fitossociológica do estrato arbóreo de uma cascalheira revegetada no Distrito Federal. Cerne, v.15, n.2, p.205-214, 2009.

Rice, C. W.; Moorman, T. B.; Beare, M. Role of microbial bioamass carbon and nitrogen in soil quality. In: Doran, J. W.; Jones, A. J. (ed.) Methods for assessing soil quality. Madison: Soil Science Society of America, 1996. p.203-215.
Rodrigues, G. B.; Maltoni, K. L.; Cassiolato, A. M. R. Dinâmica da regeneração do subsolo de áreas degradadas dentro do bioma cerrado. Revista Brasileira de Engenharia Agrícola e Ambiental, v.11, n.1, p.73-80, 2007.

Ruggiero, P. G. C.; Batalha, M. A.; Pivello, V. R.; Meirelles, S. T. Soil-vegetation relationships in cerrado (Brazilian savanna) and semideciduous forest, Southeastern Brazil. Plant Ecology, v.160, n.1, p.1-16, 2002.

Saffigna, P. G.; Powlson, D. S.; Brookes, P. C.; Thomas, G. A. Influence of sorghum residues and tillage on soil organic matter in a Australian Vertisol. Soil Biology and Biochemistry, v.21, n.6, p.759-765, 1989.

Silva, L. C. R.; Corrêa R. S. Sobrevivência e crescimento de seis espécies arbóreas submetidas a quatro tratamentos em área minerada no Cerrado. Revista Árvore, v.32, n.4, p.731-740, 2008.

Silva, L. C. R.; Sternberg, L.; Haridasan, M.; Hoffmann, W. A.; Miralles-Wilhelm, F.; Franco, A. Expansion of gallery forests into central Brazilian savannas. Global Change Biology, v.14, n.1, p.1-11, 2008.

Silveira, M. L. A. Dissolved organic carbon and bioavailability of $\mathrm{N}$ and $\mathrm{P}$ as indicators of soil quality. Scientia Agricola, v.62, n.5, p.502-508, 2005.

Silveira R. B.; Melloni, R.; Melloni, E. G. P. Atributos microbiológicos e bioquímicos como indicadores da recuperação de áreas degradadas em Itajuba/MG. Cerne, v.12, n.1, p.48-55, 2006.

Sousa D. M. G.; Lobato, E. Adubação com nitrogênio. In: Sousa D. M. G.; Lobato, E. (ed.). Cerrado correção do solo e adubação. 2.ed. Brasília: Embrapa Informações Tecnológicas, 2004. p.129-145. 